\title{
Wire and Arc Additive Manufacturing with TiC-Nanoparticle Reinforced AA5183 Alloy
}

\author{
Geir Langelandsvik ${ }^{1,2, *}$, Olav Ragnvaldsen ${ }^{2}$, Jan E. Flåm² ${ }^{2}$ Odd M. Akselsen ${ }^{1}$, and Hans J. Roven ${ }^{2}$ \\ ${ }^{1}$ SINTEF Industry, 7491 Trondheim, Norway \\ ${ }^{2}$ NTNU Norwegian University of Science and Technology, Department of Materials Science and Engineering, 7491 Trondheim, Nor- \\ way
}

\begin{abstract}
Wire and arc additive manufacturing of aluminium-ceramic composites shows great potential to produce high strength materials. By incorporation of nanoparticles in the feedstock wire, fine-grained material with low susceptibility for solidification cracking and enhanced strength can be obtained. In fact, this study utilised the novel screw extrusion method to prepare an aluminium alloy containing TiC nanoparticles. The commercial aluminium alloy AA5183 was selected for WAAM to assess and benchmark the effects of screw extrusion and TiC. The materials have been assessed in terms of microstructure, porosity content and mechanical properties. The presence of $\mathrm{TiC}$ reduced the average grain diameter by $70 \%$, while Vickers hardness increased with $13 \%$. However, number of pores per unit volume increased by one order of magnitude. The porosity is believed to stem from hydrogen introduced in the AA5183-material through screw extrusion processing, in addition to hydrogen trapping and pore nucleation on TiC nanoparticles.
\end{abstract}

\section{Introduction}

Research and engineering related to additive manufacturing (AM) of metallic materials has accelerated the last decade. The major driving forces for the extensive exploration of $\mathrm{AM}$ are the possibilities of manufacturing with shorter lead times, higher material utilisation and novel designs. The modified welding method wire and arc additive manufacturing (WAAM) is among the most intensively researched AM principles. WAAM builds components in a layer-by-layer fashion by fusion of a metallic wire. The material is strategically deposited by preprogrammed robotic or CNC manipulation on a build substrate. WAAM is considered a low-cost, high efficiency method due to a low hardware investment cost ( $\sim 120 \mathrm{k})$, cheap feedstock $(\sim 30 / \mathrm{kg}$ for aluminium), high materialand energy utilisation (close to 100\%) and high deposition rates (up to $1 \mathrm{~kg} / \mathrm{h}$ for aluminium) [1].

Additive manufacturing of aluminium alloys have been defiant for several reasons [2]. Trapped gas porosity from supersaturated hydrogen limit mechanical properties, especially fatigue [3]. The porosity content can be eliminated by appropriate use of wire feedstock, decreasing the arc heat input and application of suitable post-processing [4-6]. Several aluminium alloys have broad solidification ranges and large contraction upon solidification. The columnar dendritic growth during solidification combined with thermal contraction increases the risk of hot tearing and intergranular cracking. WAAM is therefore restricted to a limited number of aluminium alloys. WAAM materials solidify with lower cooling rate compared to pow-

*e-mail: geir.langelandsvik@ sintef.no der bed fusion (PBF) technologies, and consequently exhibit a coarser microstructure. The mechanical properties of WAAM materials are thus inferior to PBF counterparts [7].

Introduction of grain refining agents in the wire feedstock has been demonstrated for arc welding to eliminate crack susceptibility, refine the microstructure and enhance mechanical properties. Janaki Ram et al. [9] incorporated combinations of titanium, boron and zirconium to a heattreatable AA7020 Al-Zn-Mg filler wire in order to induce grain refinement in the weld fusion zone. A slight, although significant, reduction in crack susceptibility after welding was shown. The enhanced mechanical properties of the as-welded structure was attributed to the HallPetch effect due to extensive grain refinement. Sokoluk et al. [10] practically eliminated hot cracking of an AA7075 $\mathrm{Al}-\mathrm{Zn}-\mathrm{Mg}-\mathrm{Cu}$ alloy weld by introduction of titanium carbide nanoparticles. TiC served as a heterogeneous nucleation agent which altered the dendritic grain structure from columnar to equiaxed. Sales and Ricketts [11] performed WAAM with a scandium-reinforced AA5183 Al-Mg wire. Scandium is well known to promote grain refinement and increase the strength by precipitation of the $\mathrm{Al}_{3} \mathrm{Sc}$ phase [12].

WAAM with a ceramic nanoparticle reinforced aluminium feedstock has to the authors knowledge never been demonstrated. This study will examine the effects of material preparation through metal screw extrusion and addition of $\mathrm{TiC}$ nanoparticles on the microstructure and mechanical properties. The Al-Mg alloy AA5183 was selected as base material to have a direct benchmark of the WAAM materials, as this alloy is readily available as 
Table 1: Chemical composition of AA5183 Al-Mg WAAM feedstock in wt\% [8].

\begin{tabular}{ccccccc}
\hline $\mathrm{Mg}$ & $\mathrm{Mn}$ & $\mathrm{Fe}$ & $\mathrm{Si}$ & $\mathrm{Cu}$ & $\mathrm{Ti}$ & $\mathrm{Al}$ \\
\hline 4.65 & 0.66 & 0.12 & 0.15 & 0.01 & 0.11 & Balance \\
\hline
\end{tabular}

Table 2: CMT input parameters for WAAM of AA5183.

\begin{tabular}{lll}
\hline Parameter & AA5183 & AA5183-TiC \\
\hline Current (A) & 85 & 85 \\
Voltage (V) & 11.9 & 16.6 \\
Travel speed $(\mathrm{m} / \mathrm{min})$ & 0.48 & 0.48 \\
Wire feed speed $(\mathrm{m} / \mathrm{min})$ & 5.8 & 5.0 \\
\hline
\end{tabular}

WAAM feedstock. Although AA5183 has low susceptibility for solidfication cracking [13], it was selected as a proof-of-concept material for microstructural refinement.

\section{Experimental procedure}

The WAAM feedstock of interest was based on the AA5183 Al-Mg alloy. The feedstock was in form of $\phi 1.2$ $\mathrm{mm}$ wire manufactured by Safra SpA (Brescia, Italy). The alloy composition is given in Table 1 .

Two versions of the AA5183 wire were used as feedstock for WAAM; one monolithic AA5183 wire as delivered from supplier; and one modified AA5183 wire with 1 vol\% TiC nanoparticle addition (fcc crystal structure, diameter 40-60 nm). The TiC-modified wire was prepared by mixing monolithic AA5183 wire and TiC nanopowders in a screw extrusion process as described in [14]. The screw extrusion product was further processed to welding wire quality by drawing and wire shaving at the Technische Universität Bergakademie Freiberg, Germany.

WAAM was performed with a Fronius TPS 440i Cold Metal Transfer (CMT) power source. CMT short circuits the arc by dipping the filler material into the weld pool, which provides better arc stability. CMT supplies less energy to the workpiece than conventional electric arc welding, which has been shown desirable for microstructure refinement and porosity reduction [5]. The input welding parameters for the two different WAAM thin walls are given in Table 2.

The CMT torch was mounted to a six degrees of freedom robot arm (ABB IRB2400). The robot arm was pro-

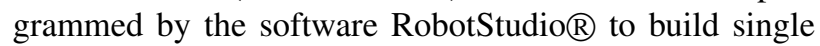
bead thin walls with dimensions as shown in Figure 1. The material was deposited along the $X$-axis in a zigzag pattern on an AA6082-T6 plate substrate with thickness $10 \mathrm{~mm}$.

Mechanical properties were examined by isostatic tensile testing along two perpendicular directions (deposition direction $X$ and through-thickness direction $Z$ ) in agreement with Figure 1. Vickers microhardness measurements with 100 grams force $\left(\mathrm{HV}_{0.1}\right)$ was performed in the frontal plane, i.e. the $Y Z$-plane. Grain morphology and size was examined in cross-polarised optical microscopy on sam-

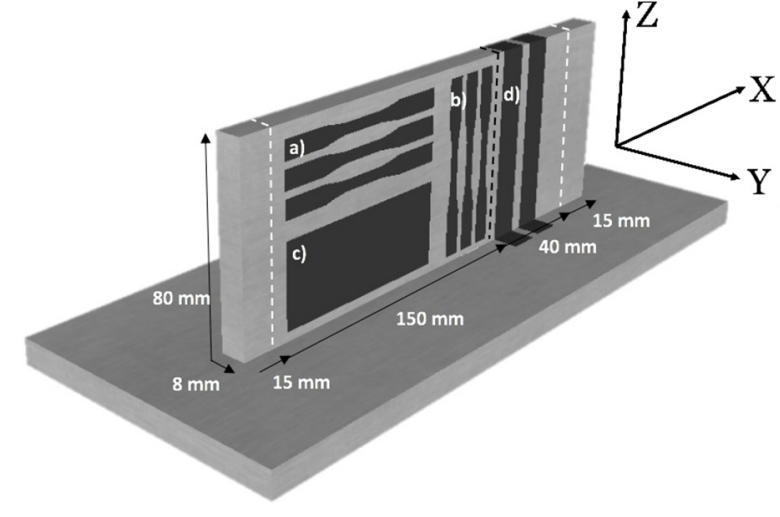

Figure 1: Reference coordinate system, dimensions and sample locations of the WAAM thin wall. a-b) Tensile specimens in deposition direction $X$ and through-thickness direction $Z$, respectively c) section for metallography and microhardness d) section for CT.

ples anodised in Baker's reagent for $180 \mathrm{~s}$. The grain size was determined by the grain intercept method. The presence of TiC was revealed by energy dispersive X-ray spectroscopy (EDS) in field emission scanning electron microscopy (SEM).

Internal porosity was inspected by X-ray computed tomography (CT). The CT data was acquired by a Nikon XT H225 ST instrument. A tungsten reflection target was used, with an acceleration voltage of $135 \mathrm{kV}$ and a current of $195 \mu \mathrm{A}$. The X-rays were not filtered. The imaging was done with an integration time of 0.708 second, amplification of $18 \mathrm{~dB}$, with 3142 projections per $360^{\circ}$. The distance from source to sample was $56.18 \mathrm{~mm}$, distance from source to detector was $1124.2 \mathrm{~mm}$, resulting in a voxel size of $10 \mu \mathrm{m}$. The images were exported in 16-bit TIFF format and processed in the public domain software ImageJ using scripts developed at SINTEF.

\section{Results and discussion}

An equiaxed grain morphology was observed in all investigated WAAM materials as shown in Figure 2. The morphology was independent of the addition of $\mathrm{TiC}$, but was rather governed by the reduced heat input from the CMT power source. A low heat input decreased the temperature gradient $G$ in the liquid weld pool, which allowed nucleation in the constitutional undercooled zone ahead of the solidification front. This observation is in accordance with earlier studies on WAAM of AA5183 [13, 15].

In fact, a reduced grain size was obtained by the addition of TiC nanoparticles. While the monolithic AA5183 


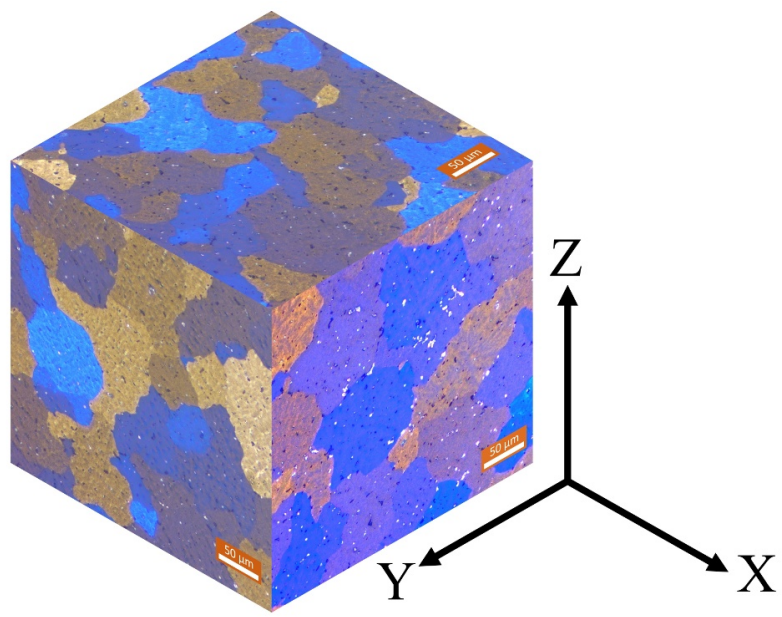

(a) AA5183

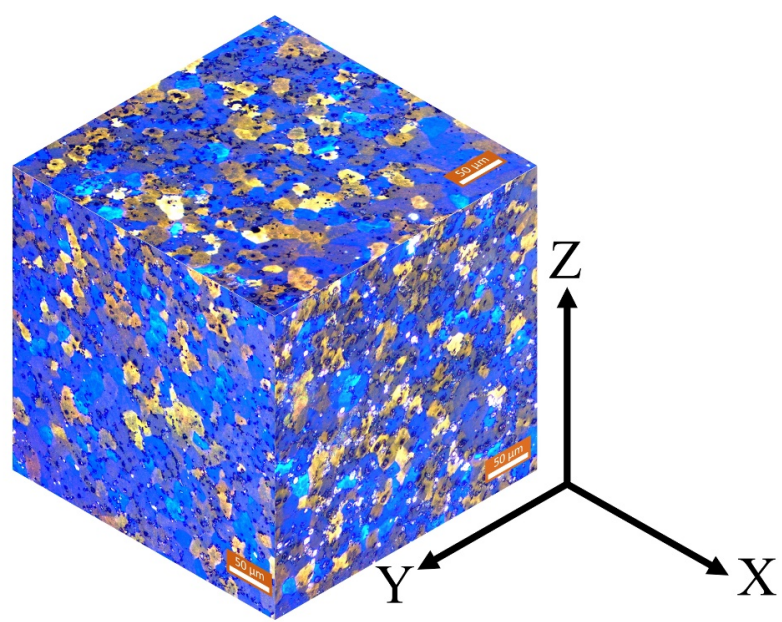

(b) AA5183-TiC

Figure 2: Microstructure in three perpendicular planes of the WAAM materials. Grain refinement was achieved in the AA5183-TiC parallel. Scale bars are $50 \mu \mathrm{m}$.

WAAM structure exhibited an average grain diameter of $60 \pm 5 \mu \mathrm{m}$, the average grain diameter was reduced to $17 \pm 1$ $\mu \mathrm{m}$ in the AA5183-TiC material. The grain refining effect can be related to heterogeneous nucleation on TiC particles upon solidification in WAAM. The constitutional supercooling required to activate a nuclei decreased with the presence of TiC nanoparticles, due to the low interface energy between aluminium and $\mathrm{TiC}$ [16]. The presence of a TiC cluster in the grain center in Figure 3 indicate that TiC may act as the heterogeneous nucleation site. The $\mathrm{Al}_{3} \mathrm{Ti}$ intermetallic was also observed in the material. Several authors have proposed this constituent responsible for grain refinement of aluminium alloys [17]. The current study has not been able to determine the grain refining phase.

Two- and three-dimensional porosity maps of the WAAM thin walls are shown in Figure 4. All cavities were solely spherical in both samples, indicating the presence of entrapped gas. The effect of screw extrusion on

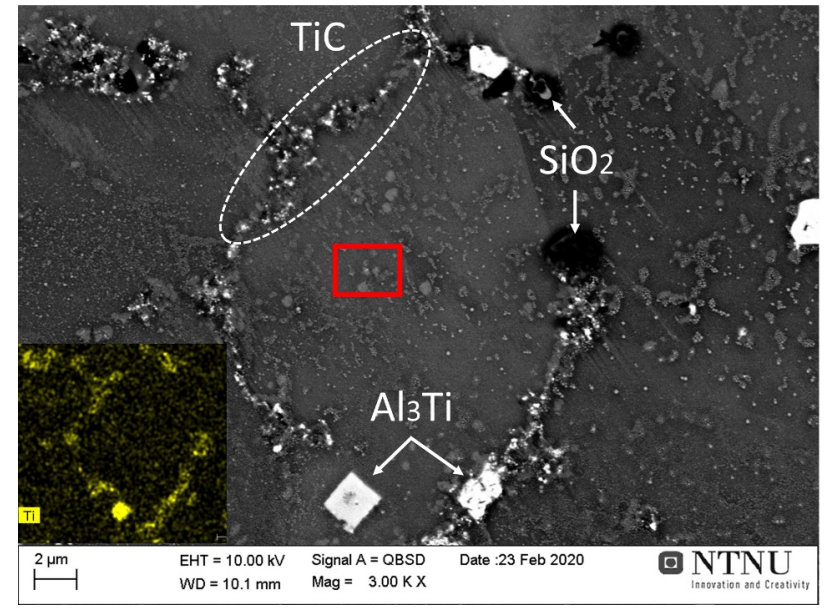

(a) Grain boundaries decorated with TiC. The red rectangle area is shown at higher magnification in $b$ ).

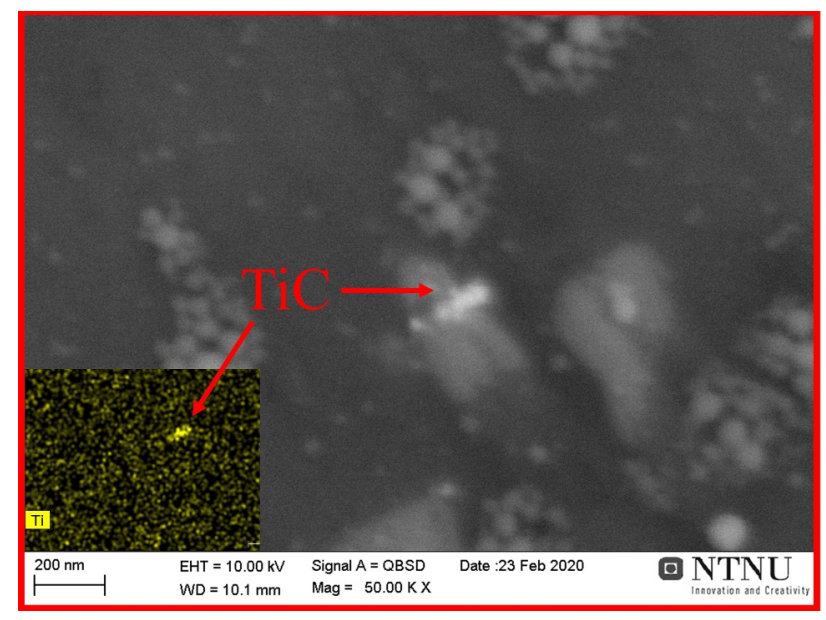

(b) Marked area from a). Possible grain nucleation site on TiC nanoparticle.

Figure 3: SEM micrographs of AA5183-TiC WAAM wall. The presence of titanium is proved by EDS (inserted images at left bottom).

the AA5183 material is shown in the lower part of Figure 4a). A mixture of micro- and macroporosity can be seen, which is believed to stem from oxidation and further hydroxation of magnesium during screw extrusion. The upper part of the WAAM material in Figure 4a) consists of screw extruded AA5183 with TiC. The porosity formation was extensive in this area. It is believed that incorporation of $\mathrm{TiC}$ accounted for the increased pore content. The commercial WAAM feedstock in Figure 4c) exhibited a repeated pore structure along the fusion line of every bead layer. Remelting and rapid solidification upon deposition of a new layer restrict hydrogen gas escape close to the fusion line, and account for the layered structure. A similar effect can also be seen in Figure 4b).

It is well-known that dissolved hydrogen in aluminium create porosity upon solidification, due to the large difference in hydrogen liquid and solid state solubility. Hydrogen can be introduced to WAAM materials in a number 


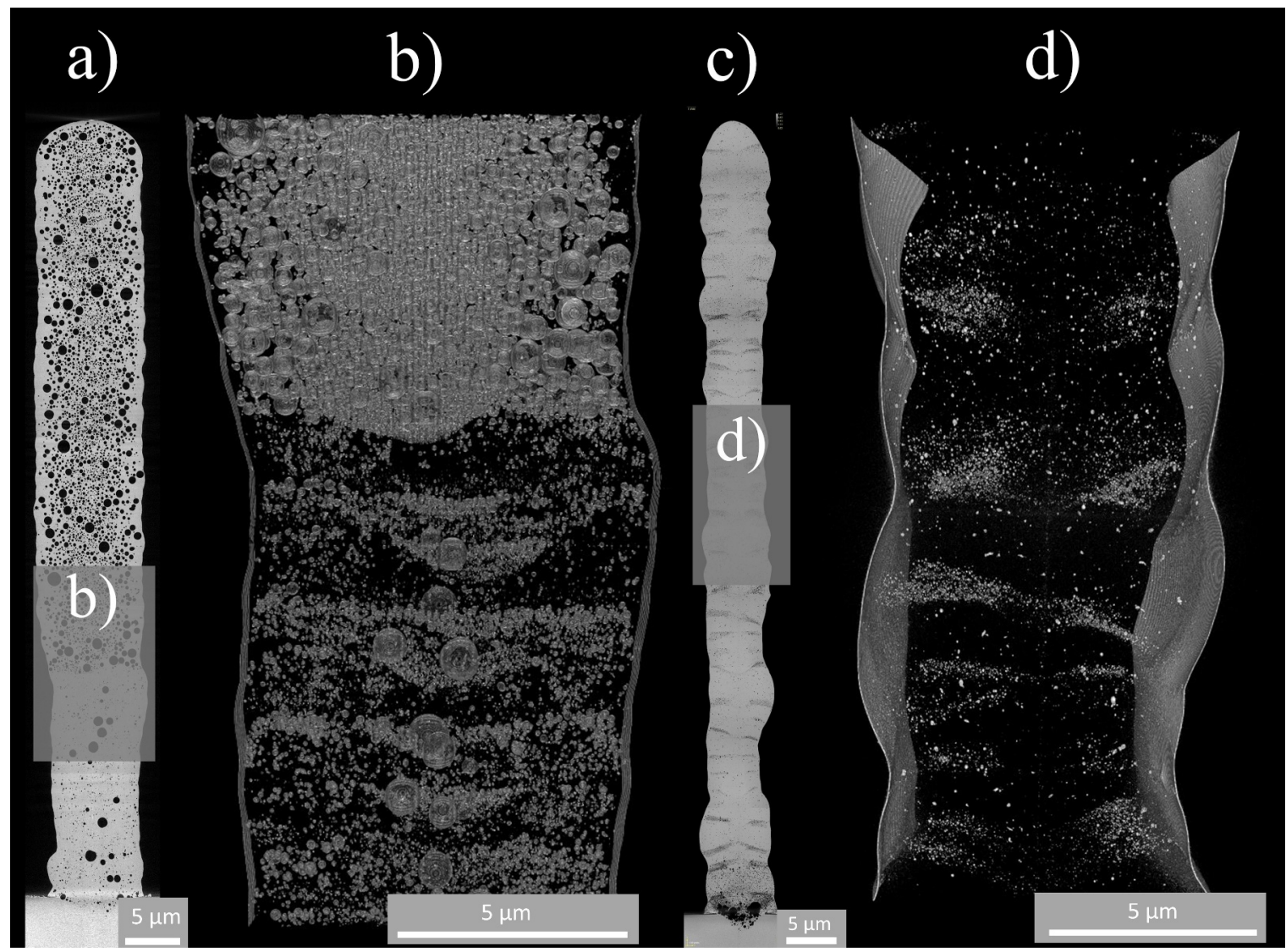

Figure 4: Computed tomograpghy scans of WAAM thin walls. a) 2D section of AA5183-TiC b) 3D reconstruction of AA5183-TiC section (50 layers) c) 2D section of AA5183 b) 3D reconstruction of AA5183 section (900 layers).

of ways. A wire feedstock with poor surface quality can cause arc instability during WAAM, which can introduce moisture from air into the weld pool. Moisture and grit on the wire surface itself is another common source of hydrogen porosity [4]. A higher heat input of the AA5183-TiC material increases the weld pool size and elevate hydrogen pick-up.

All pores detected by $\mathrm{CT}$ in a representative volume of the two WAAM materials are presented in Figure 5. Compared to the commercial AA5183 deposit, the AA5183TiC material possessed a higher pore density. The increase in porosity can be explained by the contamination of $\mathrm{TiC}$ nanoparticles in air and the feedstock preparation through screw extrusion. Screw extrusion is a solid-state processing method where metal fragments (e.g. pellets and chips) are compacted together and extruded to a solid rod [18]. In fact, metal fragment surfaces can contain (hydr)oxides, which are broken up and baked into the aluminium matrix during screw extrusion. Thus, the screw extruded AA5183-TiC wire is believed to contain a higher hydrogen content than the commercial AA5183 wire. Measures to significantly reduce the hydrogen content is still under development.

Supersaturated hydrogen is unstable in the liquid weld during solidification in WAAM, and will precipitate and form bubbles. Hydrogen trapping and subsequent precipitation is facilitated by the presence of solid interfaces, like inclusions and particles [19]. With TiC nanoparticles evenly dispersed in the weld pool, porosity formation is enhanced and resulting in a pore structure as seen in Figure $4 a-b)$.

Further, isostatic tensile results are shown in Figure 6. The tensile properties of the commercial AA5183 material were comparable to reported literature data, i.e. ultimate tensile strength 290-300 MPa [13, 20]. Anisotropy in strain between deposition direction $X$ and throughthickness direction $Z$ can be related to the layer-wise accumulation of cavities as shown in Figure 4d). The throughthickness direction $Z$ probably experienced crack growth by pore coalescence as this direction crossed several pore layers. The serrations observed in the stress-strain curves are related to the Portevin-Le Chatelier effect commonly observed in Al-Mg alloys [21].

The strength and ductility of the AA5183-TiC WAAM material were inferior due to the high porosity level. A denser material would provide a rightful comparison to the AA5183 WAAM material. However, the strength can also be assessed through microhardness. An average of minimum 15 indents revealed that incorporation of $\mathrm{TiC}$ nanoparticles increased the microhardness by $13 \%$ (from $78 \pm 5 \mathrm{HV}_{0.1}$ to $88 \pm 5 \mathrm{HV}_{0.1}$ ). Such hardness (and corresponding strength) increase can be related to a number of strengthening mechanisms. Five of these contributions from TiC, i.e. from grain refinement (Hall-Petch), load 


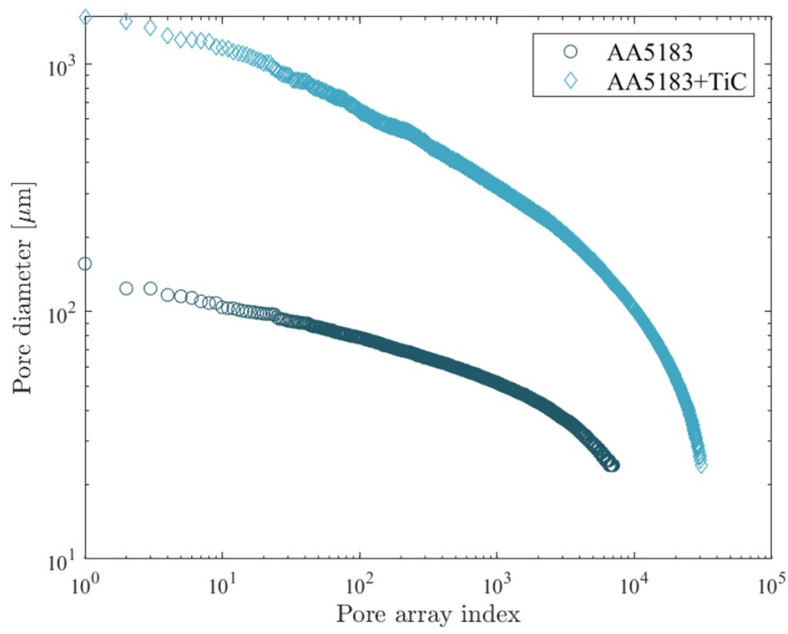

Figure 5: Pore count diagram with pore diameter sorted from largest to smallest in the WAAM materials. Measurement volume was $6 \times 6 \times 1 \mathrm{~mm}^{3}$ and one index point represent one pore. The AA5183-TiC WAAM material has a higher pore density compared to the monolithic AA5183 WAAM material.

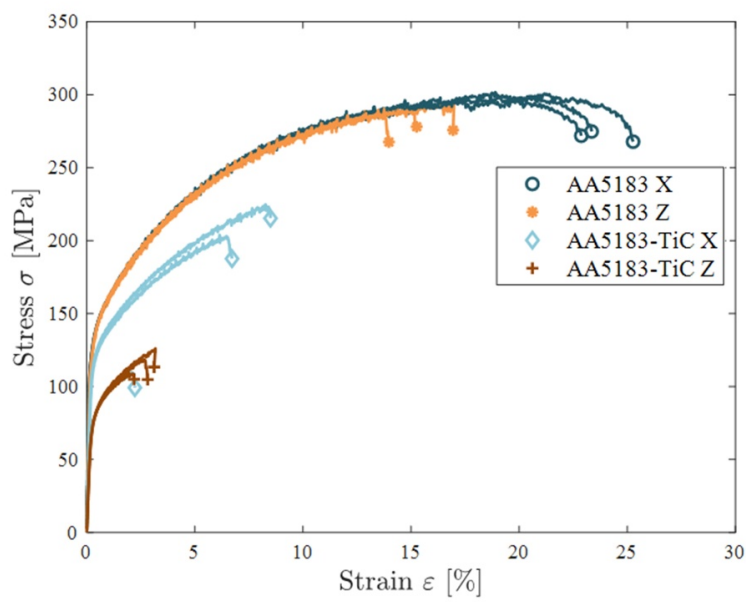

Figure 6: Isostatic tensile results for investigated WAAM materials. TiC-reinforced parallels exhibited lower strength and ductility due to a high porosity content.

transfer, elastic modulus (EM) mismatch, coefficient of thermal expansion (CTE) mismatch and Orowan strengthening, are summarised in Figure 7. Related equations and input parameters can be found in the Appendix. Recall that 1 vol\% of TiC was added to the nanoreinforced material. It is evident that for a low volume fraction of $\mathrm{TiC}(<1$ vol\%, Figure $7 b$ ), the strength and hardness contribution is governed by local strain fields from CTE mismatch.

Incorporation of potent grain refiners in the feedstock wire can expand the aluminium alloy selection for WAAM. Several alloys from, e.g., the AA6XXX Al-Mg$\mathrm{Si}$ and AA7XXX Al-Zn(-Mg-Cu) systems are considered unsuitable for WAAM in monolithic state due to solidification cracking. The cracking mechanism arise due

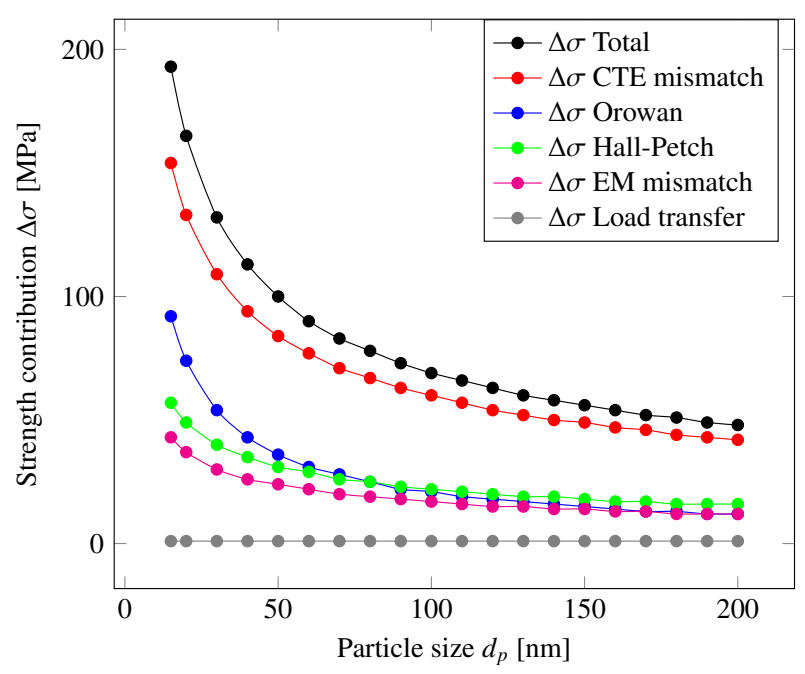

(a) Strength contribution of TiC nanoparticles with respect to particle size $d_{p}$. Volume fraction $=1 \mathrm{vol} \%$.

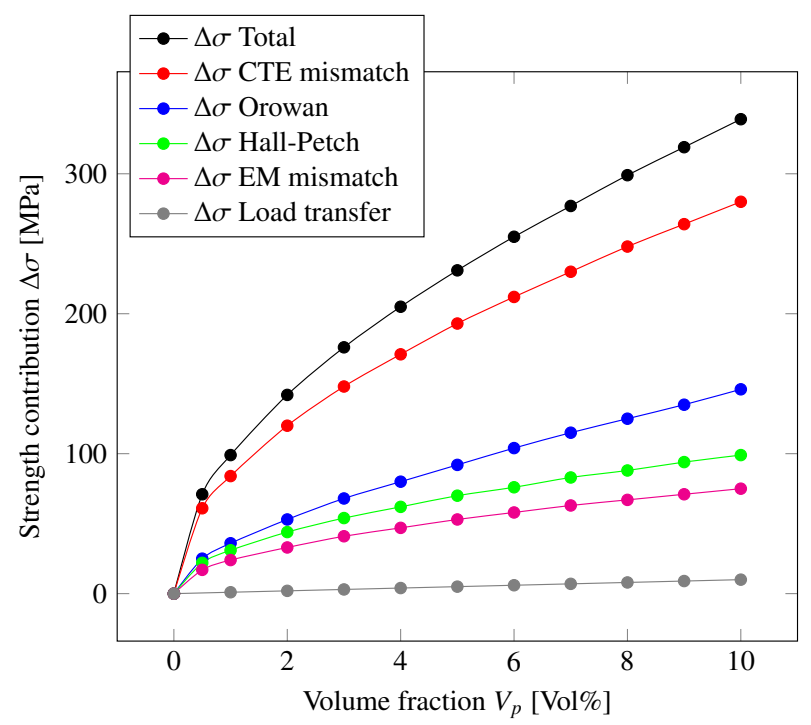

(b) Strength contribution of $\mathrm{TiC}$ nanoparticles with respect to volume fraction $V_{p}$. Particle diameter $=50 \mathrm{~nm}$.

Figure 7: Theoretical enhancement of ultimate tensile strength $(\Delta \sigma)$ from addition of TiC nanoparticles.

to an unfavourable dendritic microstructure and residual stresses from thermal contraction. By inducing a dendritic to equiaxed grain transition through addition of grain refiners, the residual stresses are distributed over a larger grain boundary area which prevent cracking. This study has worked as a proof-of-concept with a benchmark towards a commercial alloy. Future research will employ screw extruded material to produce WAAM feedstock of crack susceptible alloys from the AA6XXX and AA7XXX series.

Aluminium WAAM components with superior mechanical properties can be achieved by tailored nanoparticle additions in the near future. If high-strength aluminium alloys like AA7075 can be deposited by WAAM, components can reach a tensile strength of $\sim 550 \mathrm{MPa}$ after a post 
weld heat treatment [10]. In addition, the nanoparticles themselves can provide a further strength enhancement, Figure 7. The tensile strength contribution $\Delta \sigma$ increases with increasing particle volume fraction $V_{p}$ and decreasing particle size $d_{p}$. Thus, keeping numerous of nanosized particles evenly dispersed in the wire feedstock and deposited WAAM material is of utmost importance. The authors propose that the solid-state processing of aluminium through screw extrusion is well-suited to reach this objective.

\section{Conclusions}

The applicability of nanoparticle reinforced feedstock wires for Wire and arc additive manufacturing (WAAM) has been explored. Deposited WAAM thin walls with a TiC-modified AA5183 Al-Mg alloy exhibited grain refinement compared to a commercial AA5183 benchmark. The hardness was also increased by $13 \%$ by the addition of TiC. Tensile properties were poor due to extensive pore formation in the TiC-modified alloy.

\section{Acknowledgements}

The authors would like to thank the Research Council of Norway for financial support through Contract No. 272402. Further, the authors acknowledge Mr. Morten H. Danielsen, Mr. Nikolai Marhaug, Mr. Pål C. Skaret and Mr. Stein Rørvik for their experimental support.

\section{References}

[1] S.W. Williams, F. Martina, A.C. Addison, J. Ding, G. Pardal, P. Colegrove, Mater. Sci. Technol. 32, 641 (2016), https://doi.org/10.1179/1743284715Y. 0000000073

[2] B. Wu, Z. Pan, D. Ding, D. Cuiuri, H. Li, J. Xu, J. Norrish, Journal of Manufacturing Processes 35, 127 (2018), https://doi.org/10.1016/j.jmapro.2018. 08.001

[3] H. Toda, H. Oogo, K. Uesugi, M. Kobayashi, Materials transactions 50, 2285 (2009), https://doi.org/10. 2320/matertrans.M2009123

[4] E.M. Ryan, T.J. Sabin, J.F. Watts, M.J. Whiting, Journal of Materials Processing Technology 262, 577 (2018), https://doi.org/10.1016/j. jmatprotec.2018.07.030

[5] B. Cong, J. Ding, S. Williams, The International Journal of Advanced Manufacturing Technology 76, 1593 (2015), https://doi.org/10.1007/ s00170-014-6346-x

[6] J. Gu, J. Ding, S.W. Williams, H. Gu, P. Ma, Y. Zhai, Journal of Materials Processing Technology 230, 26 (2016), https://doi.org/10.1016/j.jmatprotec. 2015.11.006

[7] J.J. Lewandowski, M. Seifi, Annual review of materials research 46, 151 (2016), https://doi.org/10.1146/ annurev-matsci-070115-032024
[8] SAFRA, Safety data sheet, SAFRA, Brescia, Italy (2014), available at: http://www.safraspa.it/en/ msds/. Last visited 19.02.2020

[9] G.J. Ram, T. Mitra, V. Shankar, S. Sundaresan, Journal of Materials Processing Technology 142, 174 (2003), https://doi.org/10.1016/S0924-0136(03) 00574-0

[10] M. Sokoluk, C. Cao, S. Pan, X. Li, Nature communications 10, 98 (2019), https://doi.org/10.1038/ s41467-018-07989-y

[11] A. Sales, N.J. Ricketts, in Light Metals 2019 (Springer, 2019), pp. 1455-1461, https://doi.org/10. 1007/978-3-030-05864-7_182

[12] J. Røyset, N. Ryum, International Materials Reviews 50, 19 (2005), https://doi.org/10.1179/ $174328005 X 14311$

[13] A. Horgar, H. Fostervoll, B. Nyhus, X. Ren, M. Eriksson, O. Akselsen, Journal of Materials Processing Technology 259, 68 (2018), https://doi.org/ 10.1016/j.jmatprotec.2018.04.014

[14] O. Ragnvaldsen, Master's thesis, NTNU (2019), http: //hdl.handle.net/11250/2624249

[15] B. Zhang, C. Wang, Z. Wang, L. Zhang, Q. Gao, Journal of Materials Processing Technology 267, 167 (2019), https://doi.org/10.1016/j. jmatprotec.2018.12.011

[16] M.X. Zhang, P.M. Kelly, M.A. Easton, J.A. Taylor, Acta Materialia 53, 1427 (2005), https://doi.org/10. 1016/j.actamat.2004.11.037

[17] T. Quested, Materials Science and Technology 20, 1357 (2004), https://doi.org/10.1179/ 026708304225022359

[18] K.G. Skorpen, E. Mauland, O. Reiso, H.J. Roven, Transactions of Nonferrous Metals Society of China 24, 3886 (2014), https://doi.org/10.1016/ S1003-6326(14)63547-0

[19] C. Tian, J. Law, J. van der Touw, M. Murray, J.Y. Yao, D. Graham, D.S. John, Journal of Materials Processing Technology 122, 82 (2002), https://doi.org/ 10.1016/S0924-0136(01)01229-8

[20] X. Fang, L. Zhang, G. Chen, X. Dang, K. Huang, L. Wang, B. Lu, Materials 11, 2075 (2018), https: //doi.org/10.3390/ma11112075

[21] A. Benallal, T. Berstad, T. Børvik, O. Hopperstad, I. Koutiri, R.N. De Codes, International Journal of Plasticity 24, 1916 (2008), https://doi.org/10.1016/j. ijplas.2008.03.008

\section{Appendix}

All equations to estimate the tensile strength contribution from TiC nanoparticles in Figure 7 are included in Equation 1-9. Input parameters are provided in Table 3. Please note that the grain size calculation in Equation 2 is based upon Zener pinning and not heterogeneous nucleation.

$$
\Delta \sigma_{H P}=\frac{k_{y}}{d}
$$




$$
\begin{gathered}
d=\frac{4 \alpha d_{p}}{3 V_{p}} \\
\Delta \sigma_{L T}=0.5 V_{p} \sigma_{m} \\
\Delta \sigma_{\text {Orowan }}=\frac{0.81 M G b \ln \left(d_{p} / b\right)}{2 \pi(1-v)^{0.5} d_{p}\left(\frac{1}{2} \sqrt{\frac{3 \pi}{2 V_{p}}}-1\right)} \\
\rho_{E M}=\frac{6 V_{p}}{b d_{p}} \epsilon
\end{gathered}
$$$$
\Delta \sigma_{E M}=G b \lambda \sqrt{\rho_{E M}}
$$

$$
\rho_{C T E}=\frac{A \Delta C \Delta T V_{p}}{b d_{p}\left(1-V_{p}\right)}
$$$$
\Delta \sigma_{C T E}=\kappa G b \sqrt{\rho_{C T E}}
$$

$$
\Delta \sigma=\sqrt{\sum_{i} \Delta \sigma_{i}^{2}}
$$


Table 3: Input parameters for Equations 1-9 to estimate strength contribution from TiC nanoparticles.

\begin{tabular}{|c|c|c|c|c|}
\hline Parameter & Symbol & Unit & $\mathrm{Al}$ & $\mathrm{TiC}$ \\
\hline $\begin{array}{l}\text { Volume fraction } \\
\text { particles }\end{array}$ & $V_{p}$ & - & & $0.01-0.10$ \\
\hline Particle diameter & $d_{p}$ & $\mathrm{~nm}$ & & $30-200$ \\
\hline Grain size & $d$ & $\mu \mathrm{m}$ & & \\
\hline Yield strength Al & $\sigma_{m}$ & $\mathrm{MPa}$ & 200 & \\
\hline $\begin{array}{l}\text { Hall Petch } \\
\text { strengthening } \\
\text { coefficient }\end{array}$ & $k_{y}$ & $\mathrm{MPa} \mathrm{mm} m^{-1 / 2}$ & 1.8 & \\
\hline $\begin{array}{l}\text { Proportionality } \\
\text { constant }\end{array}$ & $\alpha$ & $\mathrm{nm}$ & 0.5 & \\
\hline Taylor factor & $M$ & - & 3 & \\
\hline Shear modulus & $G$ & $\mathrm{GPa}$ & 25.5 & \\
\hline Burgers' vector & $b$ & $\mathrm{~nm}$ & 0.286 & \\
\hline Poissons' ratio & $v$ & - & 0.33 & \\
\hline $\begin{array}{l}\text { Geometrical } \\
\text { factor }\end{array}$ & $A$ & - & 12 & \\
\hline $\begin{array}{l}\text { Coefficient of } \\
\text { thermal expansion }\end{array}$ & $C$ & $\mu \mathrm{m} / \mathrm{m} \mathrm{K}$ & 24 & 7.7 \\
\hline $\begin{array}{l}\text { CTE-difference } \\
\text { matrix/particle }\end{array}$ & $\Delta C$ & $\mu \mathrm{m} / \mathrm{m} \mathrm{K}$ & & 16.3 \\
\hline $\begin{array}{l}\text { Temperature } \\
\text { difference melt/test }\end{array}$ & $\Delta T$ & $\mathrm{~K}$ & 620 & \\
\hline $\begin{array}{l}\text { Uniform } \\
\text { deformation }\end{array}$ & $\epsilon$ & - & 0.01 & \\
\hline $\begin{array}{l}\text { CTE dislocation } \\
\text { strengthening } \\
\text { coefficient }\end{array}$ & $\kappa$ & - & 1.25 & \\
\hline $\begin{array}{l}\text { EM dislocation } \\
\text { strengthening } \\
\text { coefficient }\end{array}$ & $\lambda$ & - & 0.5 & \\
\hline $\begin{array}{l}\text { Strength contribution } \\
\text { from mechanism } i\end{array}$ & $\Delta \sigma_{i}$ & $\mathrm{MPa}$ & & \\
\hline Dislocation density & $\rho_{i}$ & $\mathrm{~m}^{-2}$ & & \\
\hline
\end{tabular}

